\title{
The Word Feel as an Indicator of Enacted Social Support in Personal Relationships
}

\author{
Kelly Doell ${ }^{1}$ \\ ${ }^{1}$ Department of Population Health, University of Ottawa, Canada \\ Correspondence: Kelly Doell, Department of Population Health, University of Ottawa, Ottawa, Ontario, Canada. \\ Tel: 1-613-562-5691. E-mail: kdoel018@uottawa.ca
}

\author{
Received: May 15, $2013 \quad$ Accepted: November 18, $2013 \quad$ Online Published: November 22, 2013 \\ doi:10.5539/ijps.v5n4p107 URL: http://dx.doi.org/10.5539/ijps.v5n4p107
}

\begin{abstract}
The purpose of this study was to explore the meaning attributed to the word feel and how people make sense of its use in their communication across their social network. The findings showed that the function of the word feel, in its basic form, was to emotionally self-disclose or to inquire about the private inner experiences of others. However, discursive rules dictated that it was not appropriate for all relationships. Most participants reported an open use in interdependent and supportive personal relationships. These relationships are portrayed as the most trustworthy and, through using the word feel, a source of well-being via the opportunities they provide to be cathartic and socially intimate. By contrast, the use of feel in relationships defined by dependence and vulnerability was perceived as being social risky. The word feel is portrayed as a potential indicator of enacted social support and a possible leverage point for interventions in social support.
\end{abstract}

Keywords: feel, emotion, social support, self-disclosure, reciprocation, trust, intimacy

\section{Introduction}

Self-disclosure has an important role in the process of developing and maintaining intimacy (Manne et al., 2004; Sparrevohn \& Rapee, 2009) and well-being (Prager, 1995; Greene, Derlega, \& Mathews, 2006) in relationships. In fact, negative health outcomes have been associated with people who do not or cannot engage in emotional self-disclosure (Gross, 2002; Gross \& Levenson, 1997; Zapf, 2002). However, acts of self-disclosure are not unanimously positive for a person's health and can result in such negative effects as feelings of shame, increased vulnerability, regret, and elicit specific concerns about rejection, burdening the listener, and of making an undesirable impression (Farber, 2006). As a result, acts of self-disclosure require skillful management in order to experience its positive benefits (Holtgraves, 1990).

Consequently, acts of emotional disclosure are guided by rules which dictate its appropriateness in certain contexts or relationships making it a political activity (Warner \& Shields, 2009; Shields, 2005). Hochschild $(1979 ; 1983)$ originally posited that social forces not only influence what or how people feel but also how this is shared with others. In this way, the management of emotions has been well researched. For example, burnout, stress, and anxiety have been identified as just a few of the negative consequences of inhibiting emotions (Gross \& Levenson, 1997; Pennebaker, Zech, \& Rimé, 2001; Pisaniello, Winefield, \& Delfabbro, 2012). Inhibition, in either suppressed or repressed forms, has physiological (Richards \& Gross, 1999) cognitive (Richards \& Gross, 2000) and even social costs (Butler et al., 2003; Srivastava et al., 2009). It seems that disclosing feelings, while potentially good for health, requires the careful consideration of its inherent risks.

Emotional expression can be verbal or non-verbal. However, it does not occur freely for most people even when the result of disclosing emotions can be feelings of authenticity (Farber, 2006). The considerations for appropriate or timely self-disclosure can include choices in language use to enact such an event. The function of emotionally revealing language in disclosure is unique (Greene, Derlega, \& Mathews, 2006; Mayer \& Tormala, 2010) because it can expose social norms and influence the process social support (Goldsmith, 2004). In particular, enacted social support relies on language as the means to share social resources that have direct ties to improved health (Berkman \& Glass, 2000; Kikuchi \& Coleman, 2012) like informational support (e.g., advice) or emotional support (e.g., comfort during stressful times). 
Although emotion-based language has been examined in a variety of in-depth ways (Coupland, Brown, Daniels, \& Humphreys, 2008; Gallois, 1993; Wierzbicka, 2009), the language chosen to self-disclose has received little to no specific attention in the literature. One word that is intriguing for its potential use in emotional disclosure is feel. As a result, this study explored how people make sense of the word feel across several common relationships and to examine what role it has, if any, in the process of social support.

Self-disclosure plays an important role in relationship development (Derlega, Winstead, \& Greene, 2008). On one extreme, the extended absence of meaningful social connectivity where emotional self-disclosure is infrequent yields many hardships (Pennebaker et al., 2001; Segrin \& Passalacqua, 2010). However, it is widely accepted that the number of relationships a person has in their social network is not as vital as the qualities within them (Ackerson \& Viswanath, 2009; Baum \& Ziersch, 2003; Ferlander, 2007). Qualities such as trust (Welch, Rivera, Conway, Yonkoski, Lupton \& Giancola, 2005), reciprocity (Abbot \& Freeth, 2008; Putnam, 1993) and intimacy (Merz \& Huxhold, 2010) have been shown to be three important outcomes in thriving relationships.

Welch et al. (2005) defined trust as, "the mutually shared expectation, often expressed as confidence, that people will manifest sensible and, when needed, reciprocally beneficial behavior in their interaction with others." (p. 457). Intimacy, when self-relevant feelings are shared in order to feel cared for by another, (Reis \& Patrick; 1996; Reis \& Shaver, 1988) has particular value (Prager, 1995; Prager and Buhrmester, 1998). In general, trust, intimacy, and self-disclosure have an interconnected relationship in socially supportive relationships (Greene et al., 2006; Welch et al., 2005). If emotional self-disclosure has this role in accruing some of the benefits of relationships, then understanding more about the specific verbal mechanisms involved in it could shed new light on unexplored leverage points for facilitating positive health outcomes.

Historically, social research on emotion has focused on areas such as facial expression (Campellone \& Kring, 2013), physiological activation (Kreibig, 2010), and other non-verbal displays (Knapp, 2012). Emotionally disclosing language, by contrast, has received less attention. Emotion in language use has been studied with regards to the emotional meaning of the message rather than the choice of verbiage to share such messages. Nonetheless, language is the primary tool for self-disclosure and there are several linguistic devices (e.g., $I$ believe, I think, I hope, I feel) and methods (i.e., declarations, questions, or responses) at a person's disposal.

Of the options available, the use of the word feel is an intriguing selection for disclosure. It symbolizes a window into private experience that other words do not (Fiehler, 2002). On its surface, the word feel offers a direct link to what is inherently private and emotional. Fiehler (2002) qualified the word feel as experientially declarative whether the additional information attached is an experience-designating term (e.g., I feel angry), a comparison (e.g., I felt empty), or an image (e.g., I feel as hot as the sun). It has distinct flexibility in its representative utility but, on its surface, the word feel represents inner emotional experiences much less ambiguously when compared to other disclosing verbs such as think or believe. As a result, the word feel is assumed to represent a type of conceptual glue for a category of private experience often described as affect, feelings, and emotions (Barrett, 2006). In light of this, how do people perceive the word feel and how might they manage it? Why might a person choose one word over another to perform a disclosing speech act?

Studying language that constructs identities or performs a specific action (e.g., to disclose) merits the use of discourse analysis (Searle, 1979). Discourse analysis excavates truths that are typically taken for granted (Fairclough, 1995; Parker, 1992; Potter \& Weatherell, 1987; Weatherall, Watson, \& Gallois, 2007) and that are important for understanding social and psychological realities (Willig, 2004). These truths are often experienced as sets of rules which guide actions such as who can say what to whom and when it can be said. In addition, through discourse, people assume a variety of subject positions (e.g., the caring parent, the risk taker, the unprofessional employee) which represents their agreements with the truths of the discourse including how it defines the social rules for certain behaviors (Langenhove \& Harré, 1999). This positioning has been described as "the discursive process whereby selves are located in conversations as observably and subjectively coherent participants in jointly produced story lines." (Davies \& Harré, 1990, p. 48). The rules for the different uses of certain words in a particular context or relationship facilitate the mining of the possible subject positions available through a word's different uses. These subject positions reveal the assumptions within the discourse in which the person is taking part (Butler, 2006) and are made visible through both symbols (e.g., clothing) and practices (e.g., language use) (Weedon, 2004). Importantly, circumstances like social context and relationship type can dictate the conditions of possibility that make certain subject positions available over others. 


\subsection{Research Aims}

The body of research on emotional expression, self-disclosure, and social support is vacant of rich analysis into the meaning ascribed to the word feel and its discursive rules which govern its use. Consequently, the purpose of this study was to explore the meaning attributed to the word feel and how people make sense of its use in a variety of social relationships. It did so by identifying and exploring the truths (i.e., the social rules) about the use of the word feel and how they were produced, perceived, and enacted across different types of relationships. In particular, four specific questions guided this research:

1) How do people make sense of the word feel?

2) How do people make sense of their use of the word feel across their social relationships?

3) How do people perceive their management of the word feel across their social relationships?

4) How do people construct themselves as subjects through their perceptions of the word feel?

\section{Method}

\subsection{Participants}

Fifteen participants were interviewed for this study. All participants were Caucasian, ranging in age from 19-76 with an average age of 36.0 years, 9 were female.

\subsection{Sampling, Procedure, and Materials}

Participants responded to a poster advertisement describing a study on feel at a campus health services centre. Those who showed interest were invited to contact the researcher via telephone or email. Upon doing so, an interview was scheduled to take place on the university campus where each participant was given the opportunity to review the information about the study. Audio-recorded interviews commenced after participants signed an informed consent form. Materials for data collection included an interview guide (Table 1), information form, and informed consent sheet. These materials were approved in advance by the University Ethics Review Board.

\subsection{Interviews}

Interviews ranged from 60 to 120 minutes each and explored the perceived use of the word feel with friends, siblings, parents, committed romantic partners, co-workers, strangers, as parents, and in dating (Note 1). Each interview began with a projective exercise (Soley \& Smith, 2008) whereby participants were asked to associate the word feel with a mental image and to explain their answers (see Question 1 of Table 1). Next, participants were asked to share how they perceived themselves to use the word feel in daily life. The interview subsequently narrowed focus upon participant perceptions of the use of feel across the eight common personal relationships listed above. Interviews concluded by providing participants the opportunity to share any additional beliefs about the word feel. Questions from the interview guide were supplemented by probing questions that were used to clarify responses, request further information, or invoke elaboration (Rubin \& Rubin, 2005). After transcription, interviews were sent to participants via email for authentication. No changes were requested.

Table 1. Interview guide

\begin{tabular}{|c|c|c|c|}
\hline Part One & Part Two & Part Three & Part Four \\
\hline $\begin{array}{l}\text { Q1. What images, if } \\
\text { any, come to mind when } \\
\text { you think of the word } \\
\text { feel? }\end{array}$ & $\begin{array}{l}\text { Q2. How, if at all, do you } \\
\text { use the word feel in your } \\
\text { daily life? }\end{array}$ & $\begin{array}{l}\text { Q3. How, if at all, do you use } \\
\text { the word feel with: } \\
-\quad \text { Friends } \\
-\quad \text { Siblings } \\
-\quad \text { Parents } \\
-\quad \text { As a parent } \\
-\quad \text { Romantic partner } \\
-\quad \text { In dating } \\
-\quad \text { Co-workers (Note 2) } \\
-\quad \text { Strangers }\end{array}$ & $\begin{array}{l}\text { Q4. What other } \\
\text { thoughts would you } \\
\text { like to add about } \\
\text { your use of the word } \\
\text { feel? }\end{array}$ \\
\hline
\end{tabular}




\subsection{Data Analysis}

This study focused on how individuals make sense of their use of the word feel. Discourse analysis was selected as the analytical approach. Discourse analysis is used to analyze patterns in language as clusters of themes, ideas, and images that are then used together to construct objects (Lupton, 1992). The subject positions yielded by discourse are often influenced by context, occasion, or relationship (Weatherall, 1998). In addition, Fairclough (2001) ascertained that an analysis of language elucidates the assumptions that are operating below conscious awareness. As a result, transcript analyses concentrated on (a) the discursive functions of the word feel and, (b) the rules for the suitable use of the word feel (Harré, 1986). In essence, participants were asked to connect context to their relationships in which they used or did not use the word feel.

\subsection{Data Organization}

Data analysis of each transcript began with the preparation of the transcripts (e.g., eliminating typos) and a thorough reading and re-reading of the interview text. The analytical steps that followed included creating meaning units from the data (i.e., answers to questions), identifying data themes from the meaning units (e.g., trust), and then tagging and placing the meaning units under the appropriate data theme(s) (Côté, Salmela, Baria, Russell, \& Storm, 1993). Categorized meaning units were subsequently aligned under the eight relationships in focus. Alternative cases were also recognized and evaluated for their relevance to the research questions of this study.

\section{Findings and Discussion}

In the interviews, participants reflected on the role that the word feel had in their daily lexicon. Poignantly, one participant, Ben, wondered why he concluded that the word feel required judicial management in certain situations. In doing so, he presented the most definitive rule for the use of the word feel:

In society, you are not supposed to use the word feel in conversations when you are with a certain type of person. I really don't know why off-hand. All I know is that it is different and it is probably innate for a lot of people. I really don't have an explanation for it. (Ben)

Common to discourse analysis, the focus of the interview was on making the "innate" explicit in order to bring the norms for the use of the word feel to light. Subsequently, feel was explored with greater specificity. In particular, in the sections that follow, associations of the word feel will be outlined. Next, the social functions of using the word feel will be examined. Finally, the perceptions of the use of the word will be segmented into the emergent theme of reciprocation. Specifically, this includes accounts of the word feel in unreciprocated, reciprocated, and inhibited communication. These accounts then give way to a discussion of the word feel as it pertained to themes of vulnerability, intimacy, and trust in the context of social support.

\subsection{Associations of the Word Feel}

While not all participants considered feel as broadly as Ben above, all provided a precise mental association of the word feel at the beginning of their interview. In turn, many were able to identify a link between the word feel and its specific rules of use. Foremost, participants' collective imagery depicted the word feel as associated with emotions. In addition, several accounts were supported by images pertaining to interpersonal relationships. These social-emotional associations could be negatively or positively valenced.

\subsubsection{Emotions: Positive}

Participant depictions were primarily positive and focused on desirable feelings such as happiness or love. Juliette identified an image of her grandfather in her association:

Love. Two people. My grandpa and myself I guess. What pops into mind is the feelings between two people... the feeling of love between two people. (Juliette)

Similarly, Theresa pictured positive images of close relationships that were important to her:

It's going to sound ziggy but it's something very positive. A sun hugging something! (Laughs). I don't know (pauses). I would see my family or my boyfriend or something. That's how I would envision the word feel, in an emotional family lovey-dovey way. (Theresa)

\subsubsection{Emotions: Negative}

Although positive emotions were most frequently connected to the word feel, two participants associated the word feel with negative emotions. Olivia, for instance, associated the word with anger as she recalled specific details of her relationship with her mother: 
The first thing that comes to my mind is someone angry. A feeling of fear and a picture of someone's face who is frustrated with you or angry and stuff. It's my mother. Poor woman. She and my dad had problems from before I was 5. (Olivia)

Olivia's account, while in the minority, foreshadowed a series of distinctive perspectives she would offer on the word feel. Of all participants, she appeared the most forthcoming, disclosing several details of the unpleasantness she had experienced in relationships past which had influenced how she managed the word feel afterward.

In all, feel was related to emotions with several images integrating social relations in the process. This exercise revealed unanimity across what participants associated with this word. After making these attributions, each participant was then asked how they believed they used the word in their day-to-day lives.

\subsection{Functions of the Word "Feel"}

Table 3 shows the social functions that the word feel performed (Harré, 1986). The data revealed feel as used in two ways, self-disclosure and inquiry. In the context of personal relationships, its use revealed several themes.

Table 2. Social functions of the word feel

\begin{tabular}{lll}
\hline Type of Use & Themes & Intended Outcomes \\
\hline Self-disclosure & To confess & Relief \\
& Be intimate & Closeness \\
& Seek Support & Emotional resolution \\
& Emotional support & $\begin{array}{l}\text { To unburden, to comfort, to create } \\
\text { intimacy }\end{array}$ \\
&
\end{tabular}

First, self-disclosure came in the form of confession where the intention of such disclosures was to feel unburdened or relieved from angst or tension. Secondly, feel acted as an invitation for intimacy or closeness from another party. Finally, disclosure was described as a request for support to help resolve unwanted feelings they were experiencing. That is, feel was described as useful in evoking help to resolve an issue. This differed from acts of confession because confessionals were a cathartic means to an end with no expectation for active assistance.

Its second use as inquiry represented feel as a form of questioning to evoke emotional disclosure in personal relationships. More specifically, emotional support, its most significant theme, corresponded to feel as a general act of social support through outcomes such as unburdening, comforting, or creating intimacy. These emergent themes, confession, intimacy, support seeking, and emotional support provision and their accompanying goal-orientation are supported by the literature on self-disclosure in personal relationships (Farber, 2006; Greene et al., 2006; Manne et al., 2007).

\subsubsection{Disclosure: Seek Support}

This form of disclosure reveals personal information used to facilitate a fix for an emotional concern. Jake, for instance, viewed the word feel as a means to resolve troubling feelings.

If someone makes me feel something that isn't in my normal sense of what I want to feel then I might use the word feel to tell someone I'm close with how I'm feeling. Yeah. I'd use it to describe how I feel and may be they can help me get past it and move on.

While Jake's social network appeared to provide him with options to resolve unwanted feelings in this manner, Olivia's did not. Her accounts of the word feel tended to contradict the "friends and family only" discourse revealed by others. For instance, she sought emotional intimacy with her counselor in response to her discomfort with self-disclosing to her family. Below, she described how her attitude toward self-disclosing developed:

As a kid, where do you put your feelings? I tended to be the kind of kid who internalized everything and so even from age... grade 7 ... I was in grade 7 when my mom first sent me to counselling just so I could talk to someone because I wasn't talking period. So I think it is not something I tend to use with my family. 
When asked why the word feel seemed more available in relationship with her counsellor compared to with others, Olivia continued with the following:

Probably because that's their job. They are getting paid to sit there and listen to you. You're not expected to share your emotional load in life with just anybody. Not in North America. Where I've lived, you're expected to deal with it yourself the best you can. You don't burden other people with it if you don't have to. Even with really close friends I think you withhold significant information as far as the emotional stuff.

Worrying about burdening others through self-disclosure is common (Derlega \& Winstead, 2001; Farber, 2006; Farber, Berano, \& Capobianco, 2004). However, Olivia's perspective highlighted the value of using feel with a professional care provider. Interestingly, Foucault (1983) noted that confessional relationships have been traditionally salvation-oriented. In particular, he referenced the institution of the church and how it provides resources to help an individual into the next spiritual world. Salvation, he extended, is observed in more modern ways like in the pursuit of health, well-being, and security. This form of confession draws out emotional, informational, or instrumental support with outcomes such as relief (e.g., "unburdening"), a plan for physical healing, or emotional well-being.

This emotionally supportive resource embraces self-disclosure from the emotionally vulnerable. In part, using professional care providers for support is attractive for self-disclosure because they are bound by certain codes of ethics which protect privacy and, in turn, creates trustworthiness. In this form of duty or professional care, Foucault (2000) noted, "the good ruler is precisely the one who exercises his power as it ought to be exercised, that is, simultaneously exercising his power over himself" (p. 288). Therefore, social status imbalances (e.g., expert support provider versus support seeker) observed in relationships with health-care providers generate perceptions of lower risk for those taking vulnerable positions through their use of the word feel.

Participants also shared many observations on the role of feel in soliciting support. In counselling settings like the one Olivia's participated in, feel may be a part of a confession to simply seek relief or a disclosure where her counsellor's advice is sought. While the focus of this study was on personal relationships, the word feel may also have a role in relationships with care providers in non-emotional ways. In addition to Olivia, Theresa and Ben also shared how they would use feel with an expert care provider. With their physicians, they used feel to disclose how they felt in order to obtain informational support (i.e., advice, diagnoses) or instrumental support (i.e., fixing a condition) (Berkman \& Glass, 2000). Theresa, for instance said, "If you have a doctor examining you or somebody at a medical station doing it they're going to ask you how things feel. I feel pain there. I feel pain here. Direct locations, right?" Health-care providers like doctors and nurses are in a unique position to be able to offer both forms of social support.

In general, participants showed an assortment of scenarios for using feel to acquire emotional support including these formal relationships with professional-care providers. However, examples were mostly derived from informal yet trustworthy relationships with friends, parents, and intimate partners. These personal relationships construe the core of a person's social network. This support is important to strengthening bonds because disclosing emotions, particularly when such disclosures are reciprocated, helps develop trust and intimacy (Derlega et al., 2008; Manne et al., 2007). Trust and intimacy were recurring themes associated with the use of the word feel.

\subsubsection{Disclosure: Be Intimate}

Feel was richly described as connected to creating or maintaining closeness with others. This use epitomized the original associations of feel being emotional, even intimate, in nature (Prager, 1995). Cindy and Theresa, respectively, represented intimacy in these responses:

The closer the person is to me the more likely I am to use the word feel. I've used it with my family, my husband, my parents, and my sister but less likely with acquaintances. (Cindy)

I guess everybody gets first impressions or last impressions and you can read somebody when you first meet them. So I guess a lot of it is a matter of trust, too. For me, personally, if it is someone you can trust then maybe you'd feel more comfortable. Say you're sitting in a group and there's the acquaintance there and there's good friends also there. Would you share an intimate story of what went on in your life? I think that's a judgment call. When you first meet them or you've known them for a couple of days and if that person is good friends with the others and you're good friends with the other people, I guess you would let them into your world right? (Theresa)

The content of the use of the word feel was portrayed less as a way to resolve a personal challenge (as in support-seeking) but chiefly in reference to relationship development. Theresa, for example, noted how the 
addition of someone new into a network of friends changes how she self-discloses using the word feel. Social penetration theory fundamentally identifies that a personal relationship develops as people self-disclose which, in turn, builds intimacy (Sprecher, Treger, \& Wondra, 2013). In turn, feel appeared to have a place in relationship-building for her and others.

\subsubsection{Disclosure: To Confess}

The word feel was also used as a way of resolving a psychological tension. The use of $f e e l$ in a confessional was characterized by a lack of expectation for assistance. On its own, this act provided the relief they were seeking without further problem solving. Olivia, for instance, reflected on this role as follows:

The word can release a bunch of things; either the emotional burdens a person carries or things that are more personal and possibly that evoke more emotions. I find it more personal and I would only use it with someone I knew and trusted very well. (Olivia)

Olivia's portrayal of the word feel in confession frames it as a significant, if not unique, expression. Conceivably, this is a function of carrying pent-up feelings over a period of time, released without any need for someone explicitly inquire about these feelings for her to share them.

\subsubsection{Inquiry: Emotional Support}

Another representation of the word feel in personal relationships was as an act of care or comforting. In this sense, the word feel was depicted as a way to gauge and support the well-being of others.

I use the word as a check to see if someone's okay. (...) It is very important to me how other people feel, the people I care about. When you want to know what's going on in their lives, the main thing that you're asking is how they're feeling. "How do you feel about that?" or "What are you doing about it?" Although it may not be important to me, you put yourself in their shoes and try and help them out. (Juliette)

Acts of emotional support are viewed as a fundamental provision of close relationships (Burleson, 2008; Cunningham \& Barbee, 2000). Albrecht, Burleson, \& Goldsmith (1994) defined supportive communication as communication that influences how people view themselves, their situation, and their relationship. Juliette's account of using feel in inquiry represents how it can act as a device to maintain a relationship in this way. This, again, revealed another purpose for the word feel as a significant tool to nurture bonds and deploy emotional support within one's social network.

Interpretations of the word feel framed it as a chief element of the process of emotional support with its inherent intention to emotionally unburden or comfort. Those who used the word feel typically restricted its use to personal and intimate relationships. However, Olivia's outlying accounts of her use of the word feel revealed that its management was more complex. She reserved her use of the word feel for her relationship with her counsellor who is supposed to keep, as a professional, an emotional distance from clientele. Since she showed resistance to the dominant rules, Olivia may be taking up different subject positions within the discourse that dictates that the word feel should not be used in any personal relationship. Her circumstances dictated that feel should be avoided in places where others may normally use it because her personal relationships had not been stable enough for her liking.

\subsection{Perceptions of the Use of the Word Feel across Relationships}

Feel was examined with parents, siblings, children, friends, strangers, romantic partners, co-workers and in dating relationships in the next stage of the interview. Paul's insight, below, sheds light on why this word required management and also represents several relevant patterns pertaining to trust, vulnerability, and dependency in the process of social support.

When I am talking about my feelings, I am giving someone information about me. I am letting them know how they can have an impact on me. If they are aware of it, they have a certain amount of influence over my emotional state. So I have made myself vulnerable there. But life would be dull if we didn't. (Paul)

The most poignant pattern within the data was that the perceived reciprocation of the word feel indicated interdependence within the relationship. Moreover, dependency was observed when one person required social support from the other. This dynamic meant that one person took on a vulnerable position among the rules for emotional disclosure. This will be exposed by looking at the perceived uses of the word feel across relationships where it was used in reciprocated, unreciprocated, and inhibited ways. 


\subsubsection{Reciprocated Use}

Interdependent relationships yielded the most balanced use of feel. As a result, these relationships allowed for the free use of the word. Participants shared opportunities to inquire and disclose as well as a willingness to confess, be intimate, and seek emotional assistance. The relationship that most epitomized this freedom was friendship. Participants described using the word feel openly with friends.

With friends? Without any hesitation. It will just be very spontaneous. I won't censor my thoughts. It just comes out and this is how I'm feeling and I know that it'll be accepted. (Brenda)

This portrayal showed a lack of any conscious management or suppression. In the literature, friendship has been described as one of the most important social relationships for achieving well-being (Niven, Holman, \& Tottendell, 2012). However, even amidst friends, some discretion was still reported. A cluster of friends can still exhibit variations in closeness, explaining the need to manage the word. For instance, while friendship in general was a secure relationship for the word feel, several participants cited their least inhibited use with their "best" friend. Christine represented this difference as follows:

There's a best friend and you have other friends. Your best friend is more the person you tell everything to stuff you wouldn't tell your family, things you wouldn't tell your other friends. That one person is a special relationship. You'll talk about everything; who you like, your relationships, your family and how it all makes you feel. You can actually talk to each other without worrying what they think. They won't judge you and stuff. It's definitely much easier to use the word feel with them.

Christine shared that self-disclosure, and the use of the word feel, can make a person vulnerable to undesired judgement, a concern held by several participants. Friendship can be enjoyed for its equality but social intimacy is also present in close friendships, particularly in "best" friendship. As a result, friendships are less vulnerable to the risks taken by the use of the word feel compared to other relationships.

In general, reciprocating relationships were largely depicted as non-judgemental, more intimate, and trustworthy. "I sense that I probably haven't or don't use it with someone I'm not close to or don't trust", Nadia said. "Someone I trust wouldn't judge me", she concluded. In relation, Warner and Shields (2009) described that the emotions of others are often judged by people for their appropriateness. Participant attitudes showed that they were wary of such judgement and managed their use of the word feel accordingly.

\subsubsection{Unreciprocated Use}

Outside of friendship, attitudes toward the use of the word feel were more heterogeneous. There were instances of use in all other situations but it appeared that other factors mediated its perceived management. Most accounts were associated with the vulnerable subject position that participants took on whereby they used feel for the acquisition of social support.

For example, the use of the word feel with parents was presented most often as an act of disclosure as a way to obtain emotional support. Nonetheless, instances of its use in inquiry were shared by two participants. In Juliette's case, she described her mother as being friend-like, a person with which she used the word freely:

My mom doesn't care that my boss is thinking about his goals and outcomes or how much money I made for somebody else. She just wants to make sure I'm happy and healthy and all those things. There's no way to quantify that other than using your feelings. In (my second language), "How are you?" is translated pretty much as "How are you feeling?"

However, Olivia shared otherwise. Her tenuous relationship with her parents, particularly as a youth, meant that the word feel should not be used with her parents. For her, this relationship had been historically unsupportive and emotionally uneasy:

O: I'd probably use other words but I don't think we'd use the word feel. "How are you feeling?" is a bit of a dangerous topic so... yeah.

$\mathrm{K}$ : What do you mean by dangerous?

O: Like I briefly described to you, home life was not exactly stable. So... I think it is not something I tend to bring up with my family. Generally, if you share, then that gives the other person permission to share. So the word is something I tended to avoid.

Her account showed how important social support is for using the word feel. A lack of it for Olivia meant that avoiding feel was a sensible strategy, partly because she wanted to avoid a reciprocal response where she would be expected to listen to her family's emotional disclosures or assume an emotionally vulnerable position in her 
relationship with them. Research on reciprocation indicates that it is a common aspect of social exchanges and can be described as an element of healthy social relationships but suppression, in certain circumstances, can also be a healthy coping strategy (see Greene et al., 2006). In Olivia's case, she participated in professional counselling presumably to receive the positive effects that sharing feelings in a stable and safe emotionally environment can elicit. Alternatively, healthy social networks, like a collection of good friends, would offer other options for self-disclosure. Olivia's suppressive approach was necessary for her to avoid potentially tense or hurtful conversations with her family.

\subsubsection{Mixed Reciprocation}

There was variation across the attitudes towards the word feel. This category identifies the relationships that may include reciprocation for some but not others. For example, mixed beliefs about feel were identified across participants when discussing sibling relationships. This heterogeneity is partly explainable by variations in closeness. Nadia, in particular, cited closeness as a factor in her discretion with her siblings:

I feel closer to my sibling so I would probably use it more often and in a more spontaneous and honest way. With my parents, I would be more careful using the actual word.

This provided some support for the effect of dependence on the word feel. Nadia shared that her use of the word was freer with her sibling, an interdependent relationship, noting that she, too, showed a lack of interest in disclosing with her parents. Previously, Olivia's unstable relationship with her parents seemed to create emotional distance, making her believe that her feel usage was emotionally risky. As a whole, even in stable, supportive parental relationships, reciprocation of inquiry was rarely described. This dependent relationship creates two different set of rules for the word feel. Interestingly, Fairclough (1995) recognized that how people use language is strongly determined by their family relationships implying that how feel is managed during upbringing may be perpetuated in adulthood. However, in Olivia's case, a lack of trust is likely the most significant contributing factor to her avoidance with her parents. Given her acknowledgement that self-disclosure is often reciprocated with them, her disinterest or even lack of care towards the feelings of her parents may also be a motive.

\subsubsection{Inhibited Use}

Many instances of feel avoidance were presented by participants and these accounts constituted a theme of inhibited use. For example, the greatest hesitation occurred in its use with strangers. Theresa explicated one reason for this:

I think feel is more intimate. So I don't think I would feel the need to use the word feel in a context with a stranger (...) I don't think you get into those in depth situations or conversations with them. (Theresa)

Furthermore, in Nadia's accounts of her use of feel with her family, she noted how she internalized a lot of angst towards some of her family and, like Olivia, cited that the word feel was "dangerous". This discontent, when combined with emotional strain, emerged in her memory of a significant rupture of her suppression:

My father and I would never use it. I've never used it. I honestly think the first time I used it a couple of months ago when there was a huge blow out and I had an adult reaction to it where I didn't go crying off. I said, "You really made me feel like shit, you know?" That was probably the first time I said "This is how you made me feel".

In this confrontation, the feelings that Nadia was suppressing appeared to have reached a critical mass. As a result, her inhibited emotions eventually overflowed to a point that she could not help but use the word feel to relieve this strain and assume the vulnerable position she sought to avoid. In order to feel better she had to confess these feelings even if it was within a relationship with a history of poor emotional support. This release appeared to be an honest and authentic display and shows similarities with Stiles' fever model of disclosure (1987; 1995). This model postulates that the likeliness of emotional disclosure increases as psychological distress increases. For Nadia, the accumulation of tension led to a rupture in the rule that the word feel is reserved for someone you trust.

Meanwhile, those participants who described the greatest amount of freedom in using the word feel in certain relationships established more self-sufficient positions. Parents, for example, controlled how and when the word feel was used and were themselves uninhibited in using feel as an act of inquiry. Nadia and Olivia aside, participants willingly accepted the vulnerable position that feel presented in these supportive relationships because it was safe and trustworthy to do so. 
However, one noteworthy instance materialized which showed how relationships are dynamic and can change over time. This, in turn, can also impact levels of dependence. For example, in his relationship with his father, Jerry, noted that he did not use the word feel growing up but as time passed things changed:

Growing up when I was younger, there's wasn't as much in common between us (...) Now my dad is retired, I've grown up and we have more things in common. I think it's a common thing. A coming of age thing. Yeah, we're really good friends now. I consider him a really good friend of mine. Yeah, it is definitely used more now. (Jerry)

Jerry described an emergent willingness to express himself using the word feel, perhaps due to a change in dependence. His relationship with his father appear to have developed into a friendship and signified a move toward independence and something more socially equal. In turn, this account may also showing how emotional support can develop over time.

While Jerry's inhibition eased as he grew older, an interesting outlying account of the use of the word feel was shared by another participant. As mentioned, most participants demonstrated strong hesitation with strangers. The obvious analysis of the use of feel with strangers is that, given its emotional and personal connotation, a person should not divulge this information to someone they do not know well or trust. That is, feel belongs in closer personal relationships. Intimacy, as Theresa identified earlier, was associated with the word feel by several participants. Her account showed that sharing using the word feel can be construed as an act of intimacy and trust. However, a relationship with a stranger is less defined. It is more difficult to identify with someone unknown.

These unknowns appeared to cause participants to exercise caution with the word feel, mitigating any risk from the vulnerability it can elicit. Greene et al. (2006) explained that people will typically choose non-disclosure due to fear of rejection or loss of privacy. For example, people may choose not to disclose if they feel the other party will not be helpful. Others have noted that disclosure can begin a process of establishing closeness and intimacy (Derlega et al., 2008). In seeking intimacy, the risk of non-responsiveness or, in places, social rejection was noted by participants. This makes Nancy's outlying account, below, quite intriguing.

Sometimes I find it easier to use with strangers. I've noticed a pattern in my relationships where I can get closed. It is the opposite of some people who take their time to get to know someone and then you feel more comfortable. I am kind of the opposite and I am aware of it. The closer I get, the more guarded I get. I think it stems from some family relationships that have been difficult. (Nancy)

Intimacy has been shown to be an important component of healthy social relationships (Manne et al., 2004; Reis, 2001). Given Nancy's descriptions of her relationships with the close people in her life (i.e., family, friends, partners), her account was understandable. She reported that she suffered pain in her past intimate relationships. This may be what prompted her to act outside of the rules, introducing feel in relationships where it was not normally used. Perhaps this was an effort to find intimacy in a manner that she could easily abort without much emotional risk. The social cost of emotionally self-disclosing with a stranger is minimal if it is not reciprocated or it is more forcefully rejected (Shaffer \& Tomarelli, 1989). Using feel in this way may give feelings of greater control over the word in addition to the opportunity to experience intimacy with less risk. Nancy's opportunities to disclose were reported as so few that she sought emotional self-disclosure in this way to feel socially supported.

\section{Conclusion}

The purpose of this study was to explore the meaning attributed to the word feel and how people make sense of its use across common social relationships. Overall, participants framed their accounts of the word feel within a discourse of emotional disclosure. The social function of the word feel was, in its basic form, to declare inner experiences, inquire about these experiences in others, or respond to these inquiries. In analyzing its role in a variety of social relationships, the word feel emerged as transactional, portraying a device that could be wielded to achieve certain outcomes such as to achieve intimacy, cathartic relief, and emotional comfort or to obtain solutions to problems.

This study also found that participants followed the general rule that the use of the word feel is for intimate and personal relationships. However, participant's accounts of their use of the word feel were not homogenous as evidenced by Nancy and Olivia as they resisted this rule by reproducing counter discourses with alternative truths. This heterogeneity was a welcomed product of a methodology that explored a variety of relationships rather than focusing on just one. 
Interestingly, these alternative discourses produced subject positions related to emotional disclosure that were non-intimate or impersonal in nature (e.g., with a stranger, with a counsellor). Nancy and Olivia's perspectives represented ruptures in the discourse of emotional disclosure that presumes the pre-existence of intimacy or a personal connection. It is possible that ruptures could result from inadequate opportunities to obtain emotional support in close relationships elsewhere in their social network. These cases lead them to use feel outside of its normal rules for use and to seek support in more formal relationships such as with a counsellor since they were not close with some of their family.

The literature on emotional self-disclosure pays little attention to the choices individuals make in the type of verbal mechanisms used to reveal feelings. This study shows that how people manage how they verbally self-disclose personal feelings can reveal certain qualities of the dyadic relationship in which it takes place. That is, inferences can be made about positions of interdependence, vulnerability, and the presence of trust and intimacy between two people. In addition, the word feel also shows that people may be taking on inherent risks in its use compared to other words such as think. They assume these risks ostensibly to obtain support, or a stronger depth of it, that these other mechanisms may not bring.

Goldsmith (2004) defined enacted social support as "what individuals say and do to help one another" (p. 13). These characteristics are reflected in the above portrayals of the word feel. Furthermore, recent research has suggested that enacted support be examined more for its functional components than as a general construct (Chen \& Feeley, 2012). While this study focused on personal relationships, participants referred to their relationships with professional care-providers as another context for its use. While personal relationships showed that feel was an important part of the process of emotional support, it could also be affiliated with processes of effective informational support where advice is deployed through the use of feel with patients or clients. Consequently, the word feel appears to have special qualities that conveys valuable information which may, 1) induce relief that coincides with disclosing emotions, 2) enhance the intimate connection in a relationship and, 3) assist the supporter in providing more prudent and precise support. These features all have implications for health for the discloser.

The need to socially share emotions is ubiquitous (Rimé, Corsini, \& Herbette, 2002) and this study supported that there can be many opportunities to do so across a social network. When these opportunities are unavailable, they can be sought out in more institutionalized forms. Regardless, the mechanisms for the accrual of social support are valuable for their potential to invoke positive health outcomes. Therefore, the word feel merits further investigation in interpersonal communication research and, in particular, its value in high-leverage relationships that offer direct ties to health and well-being such as those with physicians, nurses, or counselors. In this regard, there are several research questions worth exploring further. For example, what types of feel-based questions are received as the most or least supportive? What are the effects of an intervention that teaches the deployment of the word feel to health-care providers as a support skill? To do so could shed light on this word's most effective and ineffective uses. These questions would add to the foundation expounded here.

\section{Acknowledgements}

I would like to thank Dr. Christine Dallaire of the University of Ottawa for her advice and support during the research process and the development of this report.

\section{References}

Abbott, S., \& Freeth, D. (2008). Social capital and health: Starting to make sense of the role of generalized trust and reciprocity. Journal of Health Psychology, 13, 874-883. http://dx.doi.org/10.1177/1359105308095060

Ackerson, L. K., \& Viswanath, K. (2009). The social context of interpersonal communication and health. Journal of Health Communication, 14, 5-17. http://dx.doi.org/10.1080/10810730902806836

Albrecht, T. L., Burleson, B. R., \& Goldsmith, D. (1994). Supportive communication. In M. L. Knapp, \& G. R. Miller (Eds.), Handbook of interpersonal communication (2nd ed., pp. 419-449). Thousand Oaks, CA: Sage.

Barrett, L. (2006). Solving the emotion paradox: Categorization and the experience of emotion. Personality and Social Psychology Review, 10, 20-46. http://dx.doi.org/10.1207/s15327957pspr1001_2

Baum, F., \& Ziersch, A. (2003). Social capital. Journal of Epidemiology and Community Health, 57, 320-323. http://dx.doi.org/10.1136/jech.57.5.320

Berkman, L. F., \& Glass, T. (2000). Social integration, social networks, social support, and health. In L. F. Berkman, \& I. Kawachi (Eds.), Social epidemiology (pp. 137-173). New York: Oxford University Press. 
Butler, E., Egloff, B., Wilhelm, F., Smith, N., Erickson, E., \& Gross, J. (2003). The social consequences of expressive suppression. Emotion, 3, 48-67. http://dx.doi.org/10.1037/1528-3542.3.1.48

Butler, J. (2006). Gender trouble: Feminism and the subversion of identity. New York: Routledge

Campellone, T., \& Kring, A. (2013). Who do you trust? The impact of facial emotion and behavior on decision making. Cognition \& Emotion, 27, 603-620. http://dx.doi.org/10.1080/02699931.2012.726608

Chen, Y., \& Feeley, T. (2012). Enacted support and well-being: A test of the mediating role of perceived control. Communication Studies, 63, 608-625. http://dx.doi.org/10.1080/10510974.2012.674619

Côté, J., Salmela, J. H., Baria, A., \& Russell, S. J. (1993). Organizing and interpreting unstructured qualitative data. The Sport Psychologist, 6, 55-64.

Coupland, C., Brown, A., Daniels, K., \& Humphreys, M. (2008). Saying it with feeling: Analyzing speakable emotions. Human Relations, 61, 327-353. http://dx.doi.org/10.1177/0018726708088997

Cunningham, M. R., \& Barbee, A. P. (2000). Social support. In C. Hendrick, \& S. Hendrick (Eds.), Close relationships: A sourcebook (pp. 273-285). Thousand Oaks, CA: Sage.

Davies, B., \& Harré, R. (1990). Positioning: The discursive production of selves. Journal of the Theory of Social Behavior, 20(1), 43-63. http://dx.doi.org/10.1111/j.1468-5914.1990.tb00174.x

Derlega, V, Winstead, B, \& Greene, K. (2008). Self-disclosure and starting a close relationships. In S. Sprecher, A. Wenzel, \& J. Harvey (Eds.), Handbook of relationship initiation (pp. 153-174). New York: Taylor \& Francis.

Derlega, V. \& Winstead, B. (2001). HIV-infected persons' attributes for the disclosure and nondisclosure of seropositive diagnosis to significant others. In V. Manusov, \& J. Harvey (Eds.), Attribution, communication behavior, and close relationships (pp. 266-284). Cambridge: Cambridge University Press.

Doell, K. (2013). Perceptions of the use of the word "feel" in the workplace. International Journal of English Linguistics, 3, 1-14.

Fairclough, N. (1995). Language and power. London: Longman.

Fairclough, N. (2001). Critical discourse analysis as a method in social scientific research. In W. Ruth, \& M. Michael (Eds.), Methods of Critical Discourse Analysis. London: Sage. http://dx.doi.org/10.4135/9780857028020.d8

Farber, B. (2006). Self-disclosure in psychotherapy. New York: The Guildford Press.

Farber, B., Berano, K., \& Capobianco, J. (2004). Perceptions of the process and consequences of self-disclosure in psychotherapy. Journal of Counseling Psychology, 51, 340-346. http://dx.doi.org/10.1037/0022-0167.51.3.340

Ferlander, S. (2007). The importance of different forms of social capital for health. Acta Sociologica, 50, 115-128. http://dx.doi.org/10.1177/0001699307077654

Fiehler, R. (2002). How to do emotions with words: Emotionality in conversations. In S. Fussell (Ed.), The verbal communication of emotion: Interdisciplinary perspectives (pp. 79-106). Mahwah: Lawrence Erbaum Associates

Foucault, M. (1983). Afterword: The subject and power. In H. Dreyfus, \& P. Rabinow (Eds.), Michel Foucault: Beyond Structuralism and Hermeneutics (pp. 208-226). Chicago: University of Chicago Press.

Foucault, M. (2000). The ethics for the concern of the self as a practice of freedom. In P. Rabinow (Ed.), Ethics: Subjectivity and Truth: The essential works of Foucault 1954-1984 (Vol. 1). Harmondsworth: Penguin.

Gallois, C. (1993). The language and communication of emotion: Universal, interpersonal, or intergroup? American Behavioral Scientist, 36(3), 309-338. http://dx.doi.org/10.1177/0002764293036003005

Goldsmith, D. (2004). Communicating social support. New York, NY: Cambridge University Press.

Greene, K., Derlega, V., \& Mathews, A. (2006). Self-disclosure in personal relationships. In A. Vangelisti, \& D. Perlman (Eds.), Cambridge handbook of personal relationships (pp. 409-428). Cambridge: Cambridge University Press. http://dx.doi.org/10.1017/CBO9780511606632.023

Gross, J. (2002). Emotion regulation: Affective, cognitive, and social consequences. Psychophysiology, 39, 281-291. http://dx.doi.org/10.1017/S0048577201393198 
Gross, J., \& Levenson, R. (1997). Hiding feelings: The acute effects of inhibiting negative and positive emotion. Journal of Abnormal Psychology, 106(1), 95-103. http://dx.doi.org/10.1037//0021-843X.106.1.95

Harré, R. (1986). The social construction of emotions. Oxford: Basil Blackwell.

Hochschild, A. (1979). Emotion work, feeling rules, and social structure. American Journal of Sociology, 85, 551-575. http://dx.doi.org/10.1086/227049

Hochschild, A. R. (1983). The managed heart. Berkeley: University of California Press.

Holtgraves, T. (1990). The language of self-disclosure. In H. Giles, \& W. P. Robinson (Eds.), Handbook of language and social psychology (pp. 191-208). New York, NY: Wiley \& Sons.

Kikuchi, M., \& Coleman, C. L. (2012). Explicating and measuring social relationships in social capital research. Communication Theory, 22, 187-203. http://dx.doi.org/10.1111/j.1468-2885.2012.01401.x

Knapp, M. (2012). Nonverbal communication in human interaction (8th ed.). Boston, MA: Wadsworth.

Kreibig, S. (2010). Autonomic nervous system activity in emotion: A review. Biological psychology, 84, 394-421. http://dx.doi.org/10.1016/j.biopsycho.2010.03.010

Langenhove, L. V., \& Harré, R. (1999). Introducing positioning theory. In R. Harré, \& L. V. Langenhove (Eds.), Positioning theory (pp. 14-32). Massachusetts; USA: Blackwell Publishers.

Lupton, D. (1992). Discourse analysis: A new method for understanding the ideologies of health and illness. Australian Journal of Public Health, 16, 145-150.

Manne, S., Ostroff, J., Rini, C., Fox, K., Goldstein, L., \& Grana, G. (2004). The interpersonal process model of intimacy: The role of self-disclosure, partner disclosure, and partner responsiveness in interactions between breast cancer patients and their partners. Journal of Family Psychology, 18, 589-599. http://dx.doi.org/10.1037/0893-3200.18.4.589

Mayer, N. D., \& Tormala, Z. L. (2010). "Think" versus "feel" framing effects in persuasion. Personality and Social Psychology Bulletin, 36, 443-454. http://dx.doi.org/10.1177/0146167210362981

Merz, E., \& Huxhold, O. (2010). Well-being depends on social relationship characteristics: Comparing different types and providers of support to older adults. Ageing and Society, 30(5), 843-857. http://dx.doi.org/10.1017/S0144686X10000061

Niven, K., Holman, D., \& Tottendell, P. (2012). How to win friendships and trust by influencing people's feelings: An investigation of interpersonal affect regulation and the quality of relationships. Human Relations, 65, 777-805. http://dx.doi.org/10.1177/0018726712439909

Parker, I. (1992). Discourse dynamics: Critical analysis for social and individual psychology. London: Routledge.

Pennebaker, J. W., Zech, E., \& Rimé, B. (2001). Disclosing and sharing emotion: Psychological, social, and health consequences. In M. S. Stroebe, \& R. O. Hansson (Eds.), Handbook of bereavement research: Consequences, copying, and care (pp. 517-543). Washington, DC: American Psychological Association. http://dx.doi.org/10.1037/10436-022

Pisaniello, S., Winefield, H., \& Delfabbro, P. (2012). The influence of emotional labour and emotional work on the occupational health and wellbeing of South Australian hospital nurses. Journal of Vocational Behavior, 80, 579-591. http://dx.doi.org/10.1016/j.jvb.2012.01.015

Potter, J., \& Weatherell, M. (1987). Discourse and social psychology: Beyond Attitudes and Behaviour. London, U.K.: Sage.

Prager, K. J. (1995). The psychology of intimacy. New York: Guilford.

Prager, K. J., \& Buhrmester, D. (1998). Intimacy and need fulfillment in couple relationships. Journal of Social and Personal Relationships, 15, 435-469. http://dx.doi.org/10.1177/0265407598154001

Reis, H. (2001). Relationship experiences and emotional well-being. In C. Ryff, B. Singer, \& R. Davidson (Eds.), The Wisconsin symposium on emotion (pp. 57-86). New York: Oxford University Press.

Reis, H., \& Patrick, B. (1996). Attachment and intimacy: Component processes. In E. Higgins, \& A. Kruglanski (Eds.), Social psychology: Handbook of basic principles (pp. 523-563). New York: Guildford Press.

Reis, H., \& Shaver, P. (1988). Intimacy as an interpersonal process. In S. Duck (Ed.), Handbook of personal relationships (pp. 367-389). Chichester, England: Wiley. 
Richards, J. M., \& Gross, J. J. (1999). Composure at any cost? The cognitive consequences of emotion suppression. Personality and Social Psychology Bulletin, 25, 1033-1044. http://dx.doi.org/10.1177/01461672992511010

Richards, J. M., \& Gross, J. J. (2000). Emotion regulation and memory: The cognitive costs of keeping one's

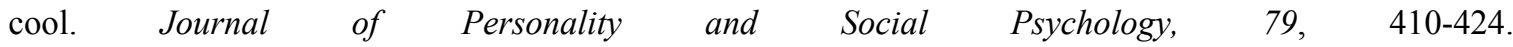
http://dx.doi.org/10.1037//0022-3514.79.3.410

Rimé, B., Corsini, S., \& Herbette, G. (2002). Emotion, verbal expression, and the social sharing of emotion. In S. R. Fussell (Ed.), The verbal communication of emotions: Interdisciplinary perspectives (pp. 185-208). Mahwah, NJ: Erlbaum.

Rubin, H., \& Rubin, I. (2005). Qualitative interviewing: The art of hearing data (2nd ed.). London: Sage.

Searle, J. (1979). Expression and meaning: studies in the theory of speech acts. Cambridge: Cambridge University Press.

Segrin, C., \& Passalacqua, S. A. (2010). Functions of loneliness, social support, health behaviors, and stress in association with poor health. Health Communication, 25(4), 312-322. http://dx.doi.org/10.1080/10410231003773334

Shaffer, D. R., \& Tomarelli, M. M (1989). When public and private self-foci clash: Self-consciousness and self-disclosure reciprocity during the acquaintance process. Journal of Personality and Social Psychology, 56, 765-776. http://dx.doi.org/10.1037/0022-3514.56.5.765

Shields, S. A. (2005). The politics of emotion in everyday life: "Appropriate emotion" and claims of identity. Review of General Psychology, 9, 3-15. http://dx.doi.org/10.1037/1089-2680.9.1.3

Soley, L., \& Smith, A. (2008). Projective techniques for social science and business research. New York: South shore Press.

Sparrevohn, R., \& Rapee, R. (2009). Self-disclosure, emotional expression and intimacy within relationships of people with social phobia. Behavior Research and Therapy, 47, 1074-1078. http://dx.doi.org/10.1016/j.brat.2009.07.016

Sprecher, S., Treger, S., \& Wondra, J. D. (2013). Effects of self-disclosure role on liking, closeness, and other impressions in get-acquainted interactions. Journal of Social and Personal Relationships, 30, 497-514. http://dx.doi.org/10.1177/0265407512459033

Srivastava, S., Tamir, M., McGonigal, K., John, O., \& Gross, J. (2009). The social costs of emotional suppression: A prospective study of the transition to college. Journal of Personality and Social Psychology, 96, 883-897.

Stiles, W. (1987). "I have to talk to somebody": A fever model of disclosure. In V. J. Derlega, \& J. H. Berg (Eds.), Self-disclosure: Theory, research, and therapy (pp. 257-282). New York: Plenum Press.

Stiles, W. (1995). Disclosure as a speech act: Is it psychotherapeutic to disclose? In J. Pennebaker (Ed.), Emotion, disclosure, and health (pp. 71-91). Washington, DC: American Psychological Association. http://dx.doi.org/10.1037/10182-004

Warner, L., \& Shields, S. (2009). Judgments of others' emotional appropriateness are multidimensional. Cognition and Emotion, 23, 876-888.

Weatherall, A., Watson, B., \& Gallois, C. (2007). Language, discourse, \& social psychology. London: Palgrave.

Weatherell, M. (1998). Positioning and interpretive repertoires: Conversation analysis and post-structuralism in dialogue. Discourse and Society, 9, 387-413. http://dx.doi.org/10.1177/0957926598009003005

Weedon, C. (2004). Identify and culture: narratives of difference and belonging. New York: NY: Mcgraw Hill.

Welch, M., Rivera, R., Conway, B., Yonkoski, J., Lupton, P., \& Giancola, R. (2005). Determinants and consequences of social trust. Sociological Inquiry, 75, 453-473.

Wierzbicka, A. (2009). Language and metalanguage: Key issues in emotion research. Emotion Review, 1, 3-14. http://dx.doi.org/10.1177/1754073908097175

Willig, C. (2004). Discourse analysis and health psychology. In M. Murray (Ed.), Critical health psychology (pp. 155-169). New York, Palgrave. 
Zapf, D. (2002). Emotion work and psychological well-being: A review of the literature and some conceptual considerations. Human Resource Management Review, 12(2), 237-268. http://dx.doi.org/10.1016/S1053-4822(02)00048-7

\section{Notes}

Note 1. Many participants could not comment on the use of the word feel across all of the relationship scenarios since not all had experience in each role (e.g., parenthood).

Note 2. The use of the word feel in the workplace is presented in a separate article (see Doell (2013)).

\section{Copyrights}

Copyright for this article is retained by the author(s), with first publication rights granted to the journal.

This is an open-access article distributed under the terms and conditions of the Creative Commons Attribution license (http://creativecommons.org/licenses/by/3.0/). 